WellBeing International

WBI Studies Repository

10-2009

\title{
Octopus insularis (Octopodidae), Evidences of a Specialized Predator and a Time-Minimizing Hunter
}

\author{
Tatiana S. Leite \\ Universidade Federal do Rio Grande do Norte \\ Manuel Haimovici \\ Laboratório de Recursos Demersais e Cefalópodes \\ Jennifer A. Mather \\ University of Lethbridge
}

Follow this and additional works at: https://www.wellbeingintlstudiesrepository.org/acwp_asie

Part of the Animal Studies Commons, Behavior and Ethology Commons, and the Comparative Psychology Commons

\section{Recommended Citation}

Leite, T. S., Haimovici, M., \& Mather, J. (2009). Octopus insularis (Octopodidae), evidences of a specialized predator and a time-minimizing hunter. Marine biology, 156(11), 2355-2367.

This material is brought to you for free and open access by WellBeing International. It has been accepted for inclusion by an authorized administrator of the WBI Studies Repository. For more information, please contact wbisr-info@wellbeingintl.org.

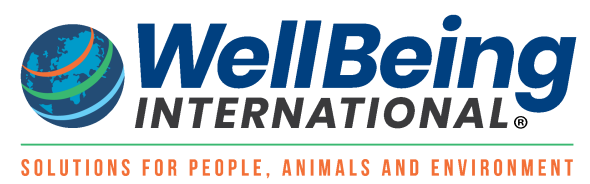




\title{
Octopus insularis (Octopodidae), evidences of a specialized predator and a time-minimizing hunter
}

\author{
Tatiana Silva Leite ${ }^{1}$, Manuel Haimovici², Jennifer Mather ${ }^{3}$ \\ ${ }^{1}$ Universidade Federal do Rio Grande do Norte, \\ ${ }^{2}$ Laboratório de Recursos Demersais e Cefalópodes (FURG), \\ ${ }^{3}$ University of Lethbridge
}

\begin{abstract}
Shallow-water octopuses have been reported as major predators of motile species in benthonic marine communities, capturing their prey by different foraging techniques. This study assessed for the first time the feeding ecology, foraging behavior, and defensive strategy during foraging, including the use of body patterns, to construct a general octopus foraging strategy in a shallow water-reef system. Octopus insularis was studied in situ using visual observations and video recordings. The diet included at least 55 species of crustaceans (70\%), bivalves (17.5\%), and gastropods (12.5\%); however, only four species accounted for half of the occurrences: the small crabs Pitho sp. (26.8\%) and Mithrax forceps (23.9\%), the bivalve Lima lima (5.3\%), and the gastropod Pisania pusio (4.9\%). Poke and crawl were most frequent foraging behaviors observed in the video recordings. The foraging behaviors were associated with environmental variables and octopus body size. The sequences of foraging behavior showed characteristics of a tactile saltatory searching predator, as well as a visual opportunist. Body patterns showed a relationship with foraging behavior, habitat variables, and octopus body size. Mottle was the most frequent pattern, especially during poke and crawl, in shallower depths. Dorsal light-ventral blue green was more frequent during swimming at midwater, and Blotch was the normal pattern during web-over by large animals. The large proportion of two species of small crabs in den remains, the intense search for food during short hunting trips, and the intense use of cryptic body patterns during foraging trips, suggest that this species is a 'time-minimizing' forager instead of a 'ratemaximizer'.
\end{abstract}

\section{Introduction}

Shallow-water octopuses have been reported as major predators of motile species in benthonic marine communities, feeding on a large number of species of crabs and mollusks, which can be captured by several foraging techniques (Ambrose 1983; Mather 1991a; Hanlon and Messenger 1996). Despite the intensive research on octopus feeding diet, especially that of Octopus vulgaris (Mather 1991a) and Enteroctopus doXeini (Vincent et al. 1998; Scheel et al. 2007), evidence is mostly indirect, that is, prey remains (Mather 1991a; Vincent et al. 1998) or stomach contents (Ibáñes and Chonge 2008). Little is known about individual hunting tactics and overall feeding and foraging strategy (Mather 1991a; Forsythe and Hanlon 1997; Anderson et al. 2008), owing to the difficulty of observing these animals in the field.

The widely accepted classic foraging models (Stephens and Krebs 1986) are based on maximizing the net rate of energy gain while foraging (time minimizers or energy maximizers). The animals are faced with two basic problems: prey choice and the optimal time to leave a food patch (Shoener 1971; Stephens and 
Krebs 1986). Fryxell and Lundberg (1998) and Stephens et al. (2007) argue that field applications of the theories probably call for more complex models that take into account variation in the size and spatial distribution of potential prey items, as well as variations in motivational state, body condition, and risk proneness of the foragers themselves.

This argument seems to be relevant, especially for foragers with varied behavior and learning. Vincent et al. (1998) and Scheel et al. (2007) clarified these complex models for octopuses, showing how many different influences there are on Enteroctopus dofleini diet, while Mather and O'Dor (1991) described the juveniles of $O$. vulgaris as intelligent opportunistic predators that have to learn the best circumstances for prey capture, the best hunting techniques, and the optimal time to move to another shelter. Another example of complexity in octopus foraging strategy is the number of prey in their diet. As generalistopportunistic predators, they prey on a wide variety of species (Ambrose and Nelson 1983; Ambrose 1984; Mather 1991a), although, as specialist predators, they also have prey preferences (Mather 1993; Vincent et al. 1998; Scheel et al. 2007; Mather, in preparation). These prey preferences vary according to the study site and the individual (Anderson et al. 2008).

Diet of octopuses can be influenced by one or a combination of several environmental variables, such as water depth (Ambrose 1984), bottom habitat (Vincent et al. 1998), and seasonal variation (Quetglas et al. 1998). These variables directly affect prey abundance and may influence the predator's choice. Diet can also shift as a function of individual predator variables, such as size (Smale and Buchan 1981) and maturity stage (Cortez et al. 1995). Since their suckers allow octopuses to hold several prey items, while foraging or eating, and capture much larger prey than the octopuses themselves, the choice of prey size may indicate the predator's strategy or prey preference, instead of a body size limitation.

Mather and O'Dor (1991) also cited search strategy and hunting techniques as important factors influencing prey choice (Anderson et al. 2008). Different search strategies could also predict different prey choices, and the three different searcher categories, "cruise searchers", "ambush searchers", (Greene 1983), and "saltatory searchers" (O'Brien et al. 1989), have different prey targets.

Shallow-water benthic octopuses are considered to be speculative hunters, assessing the habitat with their arm tips in chemotactile exploration that is the behavior of a cruise searcher (Mather 1991a; Hanlon and Messenger 1996). However, they use specific techniques to find and capture prey, such as crawl, poke or grope, web-over or pounce and pull (Mather 1991a; Forsythe and Hanlon 1997), and the last three techniques seem to be more characteristic of saltatory searchers, with the stop -and -go pattern (O'Brien et al. 1989).

Besides the two last search strategies discussed before, octopuses can also act as ambush searchers by using their eyesight (see Hanlon and Hixon 1980 for O. burryi). Although most octopuses have not been described as visual hunters during "in situ" studies (Mather 1991a; Forsythe and Hanlon 1997), laboratory experiments have described efficient visual detections and attacks on prey by octopuses (Maldonado 1964; Wells 1978; Hanlon and Wolterding 1989), suggesting that eyesight can play an important role in their foraging strategies.

One aspect of octopus foraging strategy only recently evaluated is the importance of body patterns. As predation risk can play a major role in octopus feeding strategy (Mather and O'Dor 1991; Stephens et al. 2007), the use of camouflage or other defense strategies using body patterns (see Hanlon et al. 1999), must minimize predation risk at the same time the octopus is maximizing food intake. The hypothesis that body patterns are used as an anti-predator defense mechanism while the octopus is foraging was studied for O. cyanea. Hanlon et al. (1999) and Adamo et al. (2006) tested if the changes in cuttlefish body patterns during hunting depend on prey type, prey context, or the sudden presence of a stimulus. These 
studies demonstrated that body patterns can be used as primary and secondary defense by foraging octopuses, but did not report if there is a relationship with the foraging behaviors.

To understand the complex feeding ecology and foraging strategy of the predominant octopus species (Octopus insularis) in the shallow-reef systems of the oceanic islands of Brazil, some of the variables that contribute to $O$. insularis interaction of predator avoidance and feeding ecology will be examined, including diet, ontogenic relationships, hunting techniques, and defensive strategies during foraging.

\section{Materials and methods}

\section{Background of Octopus insularis Leite and Haimovici, 2008}

Octopus insularis is a medium-sized Octopus species (the largest individual weighed 1,300 g), common in coastal Northern Brazil and its oceanic islands. It has relatively short and stout arms and a rugose reddish brown skin in preserved specimens. This species lays small eggs, has high fecundity (Leite et al. 2008) and can be found on reefs, bedrock, rubble, gravel, and sand beds and rocky bottoms, regardless of the presence of algae, but not on sandy and muddy bottoms (Leite et al. 2009).

Fig. 1 Map of Fernando de Noronha Archipelago with prey remains collection areas (cross) and areas where the foraging behaviors were WImed (1 Boldró; 2 Cagarras rasas; 3 Atalaia; 4 Sueste Bay)

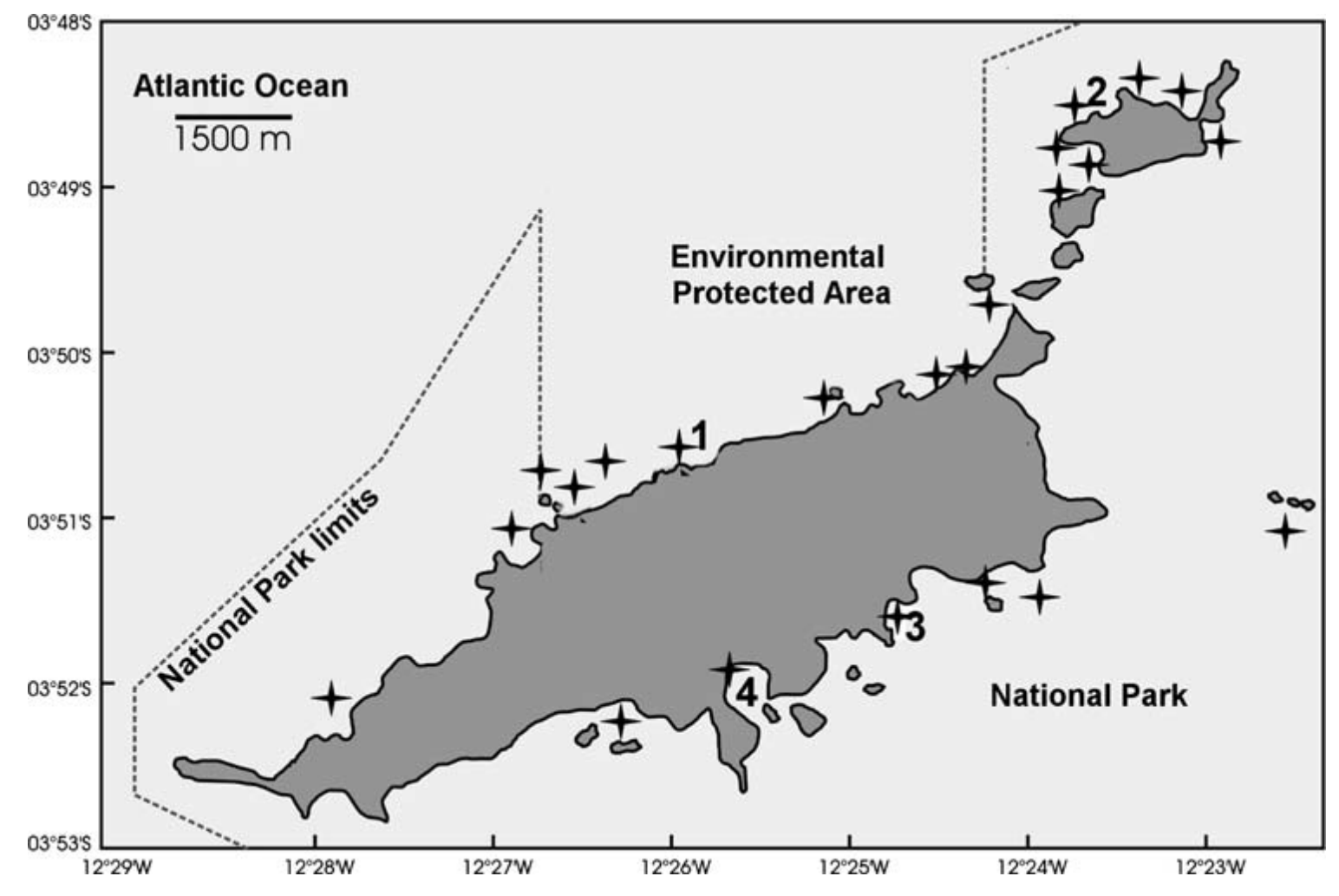

\section{Study area}

The study area was the main island of the Fernando de Noronha Archipelago, northeastern Brazilian oceanic islands, located $345 \mathrm{~km}$ NE of Cape San Roque Brazil (Fig. 1). Most of the land and the shallow 
waters around the Archipelago are part of a National Marine Park, and the remainder is an Environmental Preservation Area where some fishing is allowed (Ferreira et al. 1990).

The platform of the main island, Fernando de Noronha, is around $20 \mathrm{~km}$ in diameter and up to 100-m deep (Teixeira et al. 2003). The south and southeast shores of the island are washed by strong wave action during most of the year, and feature rocky slopes and extensive barrier reefs. Along the northern side the margins usually have gradual inclinations, with rocky slopes and large stone blocks embedded in the sand (Eston et al. 1986). There are two seasons, the rainy, from January to June and the dry, from July to December. Water temperature ranges from 23 to $27^{\circ} \mathrm{C}$ and salinity is around $36 \%$ (Eston et al. 1986).

\section{Diet and feeding strategy}

Octopuses were located during walks on emerged rocks on the near shore and by snorkeling and scuba diving between depths of 0.1 and $30 \mathrm{~m}$. Their diet was studied from hard-bodied prey remains left in midden heaps in front of octopus dens, which were identified by the simultaneous presence of the octopus and prey remains (mollusk and crustacean) (Fig. 1). Fresh prey remains had no algae growing on the inner surfaces and were unweathered. Information about octopus size, depth, and substrate was recorded. The size of the occupant octopuses was classified into four classes: "extra small (XS)" $M L<50$ mm, "small (S)" 50-80 mm ML, "medium (M)": 80-100 mm, and "large (L)" >100 mm. The depth was classified into four categories: 0-5 m; 5.1-10 m, 10-20 m, and >20 m. The substrate was characterized as bedrock or rocky and by the presence or absence of sand or rubble.

All hard-bodied prey remains in a $0.5 \mathrm{~m}$ diameter area around the den were collected. Mollusks were identified following Rios (1994), and the crustaceans following Melo (1999). Some dens were investigated for prey remains more than once, but the octopuses were counted on only one occasion. Lengths and widths (in $\mathrm{mm}$ ) of bivalve and gastropod shells and crab carapaces were measured.

\section{Statistical analyses of diet and feeding strategy}

A $t$ test was used to analyze differences between the sizes of the two most frequent prey. For each of these species, a two-way ANOVA was used to evaluate the variation in carapace size among three octopus size categories (small, medium, and large octopuses) and depth categories. The extra-small category was not included in this analysis owing to the small number of individuals observed. A two-way ANOVA was also used to evaluate the variation in the number of individual prey items in each den at the different depths $(0-5 \mathrm{~m}, 5.1-10 \mathrm{~m}$, and 10-20 m) and four octopus size categories (Statistica 6.0 software). The $>20 \mathrm{~m}$ depth category was not included because of the low occurrence of prey.

The proportion of each prey species in the remains was calculated for each den $(x)$, and this number was represented by $z=\arcsin (x)^{0.5}$ to stabilize variance (Zar 1999). Because all dens analyzed contained at least one individual from one of the four main prey species listed in Table 2, and due to the low number of other prey in the samples, the analyses were restricted to these four species, and all the other species were included in a fifth category called "minor prey species". The main effects of depth (0-5 m, 5-10 m, and 10-20 m) and octopus body size (extra-small, small, medium, and large) on the proportion of each one of the top four prey species and the minor species were analyzed as continual variables (Main effects, ANOVA, GLM procedure, Statistic 6.0).

The main effects of four environmental variables: substrate (hard, rocky), sand (presence or absence), sea area (southern and northern sides of the main island), and season (dry or rainy) (independent variables) on the proportion of the four most common species and the minor species, as multiple dependent variables, were examined by a multivariate analysis of co-variance (main effects-MANCOVA, 
GLM procedure, Statistic 6.0), with depth categories of the dens as continuous co-variants. The overall significance of each variable was determined using Wilks' Lambda. MANOVA is a method for comparing the population means of all variables of interest at the same time. It also considers the correlation among multiple variables, which separate ANOVAs cannot do (Zar 1999). All relationships were considered significant if $p<0.025$. This value was defined as a function of the number of variables tested using the same data.

\section{Foraging behavior}

Twelve octopuses were filmed during foraging trips for a total time of $2 \mathrm{~h}$. Foraging sequences were recorded underwater with a Sony mini-DV camcorder and a Canon 5.0 digital camera (films with minimum of $320 \times 240$ pixels). Filming was done during daytime under natural light $(n=12)$ and at night time with artificial light $(n=3)$ in four areas around the archipelago (Fig. 1). When an octopus was found during a foraging trip, it was followed and filmed intermittently, at a minimum distance of $0.5 \mathrm{~m}$ so as not to disturb it. The methodology chosen to analyze the behavior was the focal behavior technique (Martin and Bateson 1993). Film duration varied from 3 to $30 \mathrm{~min}$. The size of each octopus was classified into three categories: small $<80 \mathrm{~mm} \mathrm{ML}$, medium $80-100 \mathrm{~mm} \mathrm{ML}$, and large $>80 \mathrm{~mm} \mathrm{ML}$. Conspicuous body pattern, behavior and habitat characteristics were used to exclude other octopus species (Leite and Haimovici 2006).

Table 1 Habitat description of the four foraging behavior areas

\begin{tabular}{|llll|}
\hline Areas & Associated habitats & General characteristics & Depth (m) \\
\hline Atalaia & Bed rock and sand & Bed rock with sand patches in intertidal zone & $0-0.5$ \\
Boldró & Reef crest & Unbroken algacea reef in intertidal zone & $0-0.5$ \\
Cagarras rasas & Deep reef with big rocks & $\begin{array}{l}\text { Bed rock substrate with large rocks piled up (<1 m } \\
\text { diameter) in deeper water }\end{array}$ & $8-15$ \\
Sueste & \multirow{2}{*}{ Bed rock without sand } & $\begin{array}{l}\text { Unbroken bedrock with no sand patches in shallow } \\
\text { water }\end{array}$ & $0.5-2$ \\
& Small rocks and rubble & $\begin{array}{l}\text { Small rocks spread (>1 m diameter) over a rubble } \\
\text { and algae bottom, in shallow water }\end{array}$ & \\
\hline
\end{tabular}

The films were analyzed using a film editing program (Virtual Dub 1.5.10). They were stopped every $10 \mathrm{~s}$ or at shorter time intervals if the foraging behavior changed, and six variables were recorded: behavior, body pattern, body movement, substrate (rocky: spaced rocks or unbroken rock), and presence of sand or rubble. To facilitate the analyses, each behavior noted at each change was called "instantaneous behavior" (IB), which was separated into two subcategories: "instantaneous foraging behavior" (IFB), when the octopuses were actively looking for prey and "instantaneous moving behavior" (IMB): when the octopuses were only moving along the substrate. We also classified the general habitat of each area in which the octopuses were filmed, based on the type of substrate, depth, and presence or absence of sand and rubble. Five different habitats were identified in the four areas surveyed (see Table 1).

Some of foraging behavior categories observed in this study followed those described by Mather (1991a): crawl (C), web-over (WO) and poke (P), and others followed those described by Forsythe and Hanlon (1997): sitting (Si), swimming forward (SF), and swimming backward (SB). In addition, new foraging behavior categories were described: exploring rock sides (ERS), in which the octopus searched for food with four arms spread along both sides of a rock (not below, and not in crevices), without spreading its web; attack with arms (AA) (see Fig. 7), in which the octopus tried to catch prey, especially fish, by quickly 
throwing more than one arm toward it without moving along the substrate or with a small movement; removing sand (RS), where the octopus dug sand or mud with some of its arms; moving (M), the animal moves its body only a small distance $(<1 \mathrm{~m})$ along the substrate, without extending its arms laterally. The pull and consume behaviors (Mather 1991a) were not considered in these studies, because it was impossible to distinguish them in the foraging behavior films, since we did not interfere with the animals in any way, to minimize human impact on their behavior. The body patterns analyzed were the same as those described by Leite and Mather (2008): mottle (M), blotch (B), uniform dark (UD), dorsal light-ventral bluegreen (DL-VBG), and pale (P).

\section{Statistical analyses of foraging behavior}

We excluded from the statistical analyses all instances in which more than one behavior occurred. Because of the small number of observations, attack with arms (AA) and removing sand (RS) behaviors were also excluded.

Multiway contingency analysis was used to analyze if the occurrence of the three main IFB categories (crawl, poke, web-over) were correlated with the five general habitats in which the octopuses were filmed ( 3 x 5 contingency table) (SPSS 11.5; Zar 1999). The relationship between IMB categories and habitat was not analyzed owing to the small number of observations. This analysis tests the hypothesis that the occurrence frequencies in the various categories of one variable are independent of the frequencies in the second variable. Because the variables were categorical, with no intrinsic order, we chose the contingency coefficient (CC) as the measure of significance. The relationship was deemed significant if $p<0.005$.

To evaluate if $O$. insularis followed a fixed or flexible foraging behavior sequence, the number of transitions from one foraging behavior category to another was totaled in a two-way act transition matrix across all animals (Mather 1986). Sequential probabilities were calculated for five common foraging behaviors: crawl, poke, web-over, moving, and swimming. The swimming forward and swimming backward behaviors were considered as a single category. The chi-square test of observed versus expected cell frequencies was carried out to test for regularities in the transitions. The expected frequencies for each transition were calculated by the multiplication of total frequency observed of each behavior involved at the transition sequence. For example, the expected frequency of the transition between the behaviors crawl and poke was $0.33 \times 0.32=0.11=11 \%$. Transition matrices were also produced separately for each habitat, to test if the behavior transition frequencies are significantly different among the habitats. A chi-square was also used to compare the frequency observed in each habitat compared to the others.

The relationship between individual (octopus size) and environmental variables (depth, substrate, presence or absence of sand and/or rubble) and the occurrence of the three main foraging behaviors (crawl, poke and web-over) was evaluated by multinomial logistic regression (main effects). The effects of all these previously variables in addition to the swimming and moving behavior categories on the four main body patterns (blotch, mottle, uniform dark, and dorsal light and ventral blue) were also assessed.

Multinomial logistic regression is useful for classifying subjects based on the values of a set of independent nominal variables. This type of regression is similar to logistic regression, but it is more general because the dependent variable is not restricted to two categories (Zar 1999). Parameter estimation was performed through an interactive maximum-likelihood algorithm. The correlations were deemed significant at $p<0.025$. 


\section{Results}

Diet

A total of 155 collections were made from 117 dens of $O$. insularis individuals. There were 473 items of prey, classified into 55 taxa of crustacean (70\%), bivalve (17.53\%), and gastropod (12.47\%) species. Despite the large number of different prey species, only four contributed more than $5 \%$ of all occurrences: Pitho sp. (26.8\%), Mithrax forceps (23.9\%), Lima lima (5.3\%), and Pisania pusio (4.9\%). Each of 13 other prey species contributed over $1 \%$ of the total occurrences and together with the top four species totaled more than $80 \%$ of the total number of individuals found as remains (Table 2). Of the 117 dens analyzed, 116 contained at least one individual from the top four prey species listed in Table 2.

Feeding strategy

Prey size and number

The two main prey species (Pitho sp. and Mithrax forceps) were used in the analysis of prey size variation because they represented over $50 \%$ of total prey. These two crabs had similar ranges of carapace width (CW) (7.7 to $21 \mathrm{~mm}, n=115$; and 8 to $21 \mathrm{~mm}, n=105)$, but their mean size was significantly different (Pitho sp. $=11.53 \mathrm{~mm}, \mathrm{SD}=2.1 \mathrm{~mm}$; and $M$. forceps $=14.13 \mathrm{~mm}, \mathrm{SD}=2.8 \mathrm{~mm})(t$ test,$t=-7.99$, $d f=218, p<0.005$ ) (Fig. 2). Although the mean size of Mithrax forceps slightly increased with octopus size, the difference was not significant $(p>0.05)$. In addition, no significant difference with depth was observed $(p>0.05)$.

The number of prey items per den varied from 1 to $26(x=4$; SD = 4.51). Although the number of items in the dens increased with octopus size, the difference was not significant (ANOVA, $p>0.05$ ). On the other hand, the mean number of items varied significantly with depth (ANOVA, $d f=2, F=3.23, p<0.05$ ), with four items in dens between 0 and $5 \mathrm{~m}, 5.7$ items in dens between 5 and $10 \mathrm{~m}$, and 2.5 items between 10 and $20 \mathrm{~m}$. No hard-bodied prey remains were found at depths greater than $20 \mathrm{~m}$ (Fig. 3).

\section{Proportion of common prey}

To determine changes in diet with octopus size and depth, the effect of these variables on the proportion of the four main prey species and the pooled "minor prey species" was analyzed (Table 2). The proportion of any prey species and the pooled category did not vary across the octopus size categories $(p>0.05$ for all), but some of them changed across depth (Fig. 4). There was a greater proportion of Lima lima at mid depth $(F=5.44, d f=2, p<0.05)$, compared with the shallower level and there were more Pitho sp. at shallower depths $(F=6.08, d f=2, p>0.05)$. Mithrax forceps, Pisania pusio, and the pooled minor species did not vary with depth $(p>0.05)$.

The association between diet and environmental variables was investigated. The proportion of the four major prey species and the pooled minor species in each den was analyzed against depth, substrate, location, and season. Only season showed an overall significant effect on diet changes (MANCOVA: $F=3.77, d f=5, p<0.025)$. Mithrax forceps was more abundant in middens during winter, while the minor species were more abundant during summer.

\section{Foraging behavior}

Of the 315 instantaneous behaviors (IB) of 12 octopuses ( 5 small, 3 medium, and 4 large), $80 \%$ of the IB showed octopuses searching for food, whether moving or not (IFB). They were only moving along the 
substrate in $49 \%$ of observations. When octopuses were searching for food (IFB) the most frequent foraging behaviors observed were poke (37\%) and crawl (34.6\%) (Fig. 5).

Table 2 Prey of Octopus insularis $(n=473)$ (which represent $1 \%$ or more of prey consumed) found in midden remains in the Fernando de Noronha Archipelago between 2003 and 2005

\begin{tabular}{|c|c|c|c|c|c|}
\hline Taxon & Species & $\begin{array}{l}\text { Total } \\
\text { number }\end{array}$ & Percent & $\begin{array}{l}\text { Den } \\
\text { occurrence }\end{array}$ & Percent \\
\hline Crustacea & Pitho sp. & 127 & 26.8 & 55 & 35.48 \\
\hline Crustacea & Mithrax forceps & 113 & 23.9 & 61 & 39.35 \\
\hline Bivalve & Lima lima & 25 & 5.3 & 9 & 5.81 \\
\hline Gastropoda & Pisania pusio & 23 & 5.0 & 11 & 7.10 \\
\hline Crustacea & Microphrys sp. & 21 & 4.4 & 13 & 8.39 \\
\hline Crustacea & Xanthodius denticulatus & 18 & 3.8 & 15 & 9.68 \\
\hline Crustacea & Mithrax hemphilli & 14 & 3.0 & 11 & 7.10 \\
\hline Bivalve & Chione pubera & 14 & 3.0 & 4 & 2.58 \\
\hline Gastropoda & Cypraea cinerea & 11 & 2.3 & 5 & 3.23 \\
\hline Gastropoda & Nerita ascensionis & 8 & 1.7 & 4 & 2.58 \\
\hline Bivalve & Codakia orbicularis & 7 & 1.5 & 5 & 3.23 \\
\hline Crustacea & Mithrax verrucosus & 6 & 1.3 & 4 & 2.58 \\
\hline Bivalve & Chione sp. & 6 & 1.3 & 5 & 3.23 \\
\hline Bivalve & Chlamys sp. & 6 & 1.3 & 3 & 1.94 \\
\hline Bivalve & Chione cancellata & 5 & 1.1 & 2 & 1.29 \\
\hline Bivalve & Chione subrostrata & 5 & 1.1 & 2 & 1.29 \\
\hline Bivalve & Trachycardium magnum & 5 & 1.1 & 2 & 1.29 \\
\hline Crustacea & Calappa gallus & 4 & 0.8 & 3 & 1.94 \\
\hline Crustacea & Calappa ocellata & 4 & 0.8 & 2 & 1.29 \\
\hline Crustacea & Mithrax sp. & 4 & 0.8 & 4 & 2.58 \\
\hline Bivalve & Chlamys sentis & 4 & 0.8 & 4 & 2.58 \\
\hline Crustacea & Calappa sp. & 3 & 0.6 & 3 & 1.94 \\
\hline Crustacea & Chorinus heros & 3 & 0.6 & 3 & 1.94 \\
\hline Crustacea & Plagusia depressa & 3 & 0.6 & 3 & 1.94 \\
\hline Gastropoda & Brachidontes exustus & 3 & 0.6 & 3 & 1.94 \\
\hline Gastropoda & Cancelaria sp. & 3 & 0.6 & 2 & 1.29 \\
\hline Bivalve & Modiolus americanus & 3 & 0.6 & 2 & 1.29 \\
\hline Crustacea & Chorinus sp. & 2 & 0.4 & 2 & 1.29 \\
\hline Crustacea & Mithrax hispidus & 2 & 0.4 & 2 & 1.29 \\
\hline Crustacea & Parribacus sp. & 2 & 0.4 & 2 & 1.29 \\
\hline Crustacea & Portunos sp. & 2 & 0.4 & 2 & 1.29 \\
\hline Crustacea & Dromia sp. & 1 & 0.2 & 1 & 0.65 \\
\hline Crustacea & Macroceloma sp. & 1 & 0.2 & 1 & 0.65 \\
\hline Crustacea & Majidae & 1 & 0.2 & 1 & 0.65 \\
\hline Gastropoda & Astraea tecta & 1 & 0.2 & 1 & 0.65 \\
\hline Gastropoda & Columbella mercatoria & 1 & 0.2 & 1 & 0.65 \\
\hline Gastropoda & Conus sp. & 1 & 0.2 & 1 & 0.65 \\
\hline Gastropoda & Diadara sayi & 1 & 0.2 & 1 & 0.65 \\
\hline Gastropoda & Natica sulcata & 1 & 0.2 & 1 & 0.65 \\
\hline Gastropoda & Nerita sp. & 1 & 0.2 & 1 & 0.65 \\
\hline Gastropoda & Nodilittorina vermeiji & 1 & 0.2 & 1 & 0.65 \\
\hline Gastropoda & Olivella livia & 1 & 0.2 & 1 & 0.65 \\
\hline Gastropoda & Olivella sp. & 1 & 0.2 & 1 & 0.65 \\
\hline Gastropoda & Persicula sagittata & 1 & 0.2 & 1 & 0.65 \\
\hline Gastropoda & Tonna maculosa & 1 & 0.2 & 1 & 0.65 \\
\hline Bivalve & Corbula sp. & 1 & 0.2 & 1 & 0.65 \\
\hline Bivalve & Lioberus castaneus & 1 & 0.2 & 1 & 0.65 \\
\hline Bivalve & Ventricolaria rigida & 1 & 0.2 & 1 & 0.65 \\
\hline
\end{tabular}




\section{Foraging and habitat}

Figure 6 shows the relationship between IFB categories and the five general habitats (see Table 1). Crawl was the most frequent IFB on bed rock without sand, deep reefs, and the intertidal reef crest (in more than $50 \%$ of the IFB in these habitats). Web-over was the most frequent on rock and rubble, while poke was the most frequent on bed rock with sand ( $3 \times 5$ contingency table, $n=227$, contingency coefficient $(C C)=0.549, p<0.005)$.

When the animals moved through the habitat without searching for food (IMB, $n=63$ ), the most frequent behavior recorded was moving (45\%) followed by swimming backward (41\%).

Fig. 2 Carapace width distribution of the two main prey species (Pitho sp., $n=115$ and Mithrax forceps, $n=$ 105) collected in den remains of Octopus insularis in Fernando de Noronha Archipelago

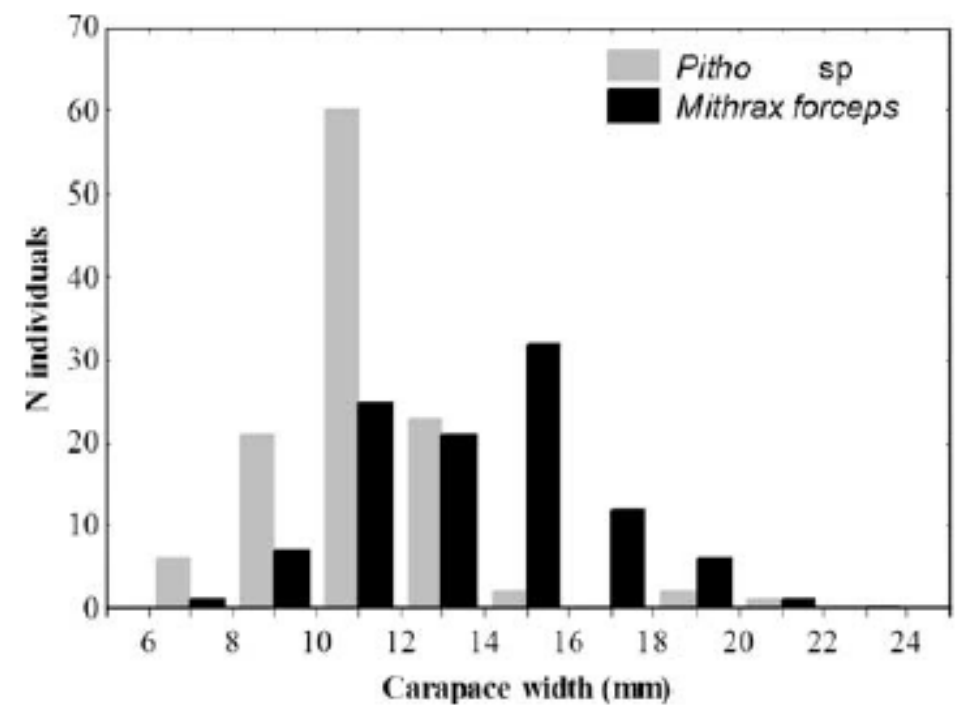

Fig. 3 Number (mean and 95\% confidence interval) of Octopus insularis individual prey items per den at different depth ranges

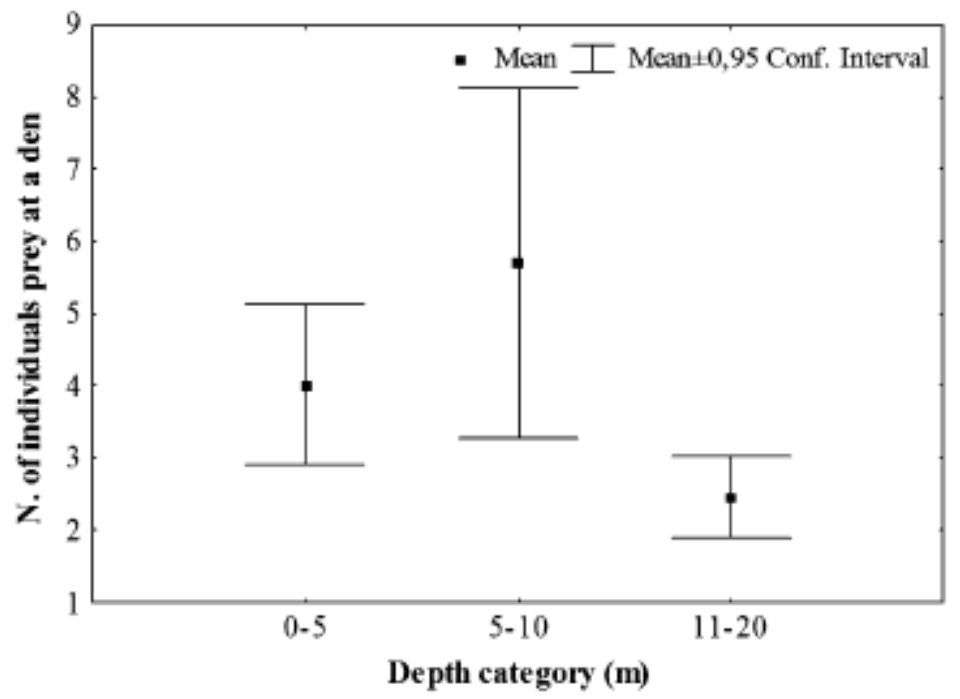


Fig. 4 Proportion of each of the four most common Octopus insularis prey species and the pooled minor species, in the middens of dens at different depth ranges

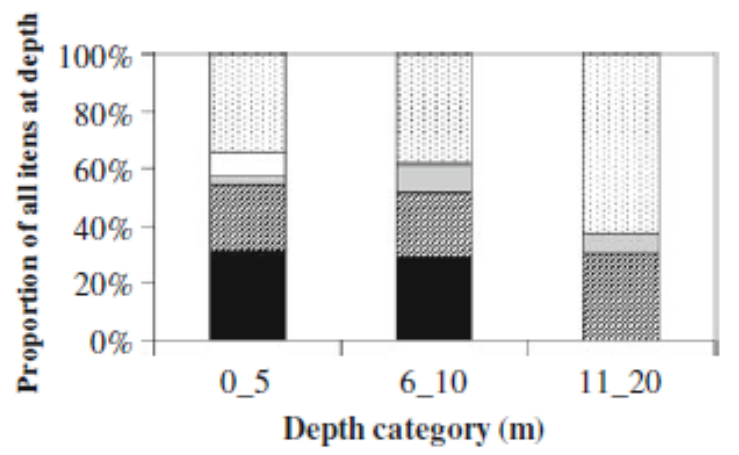

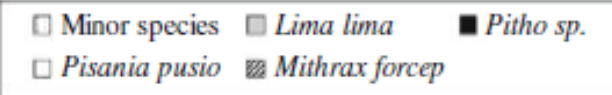

Fig. 5 Percentage of occurrence of the foraging behavior in the instantaneous foraging behaviors observed on the 0 . insularis video recordings

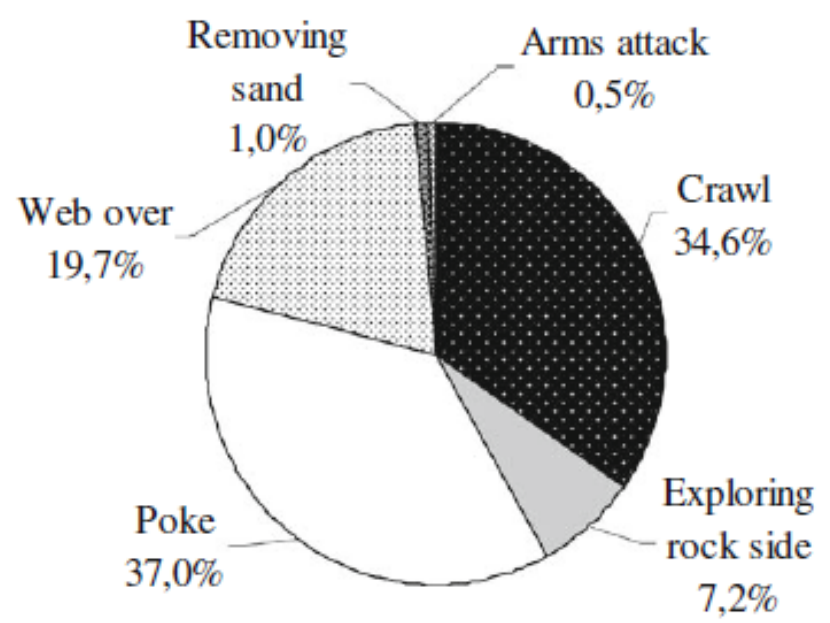

Fig. 6 Percentage of occurrence of the main foraging behavior observed on the 0 . insularis video recordings, in the five habitats where they occurred

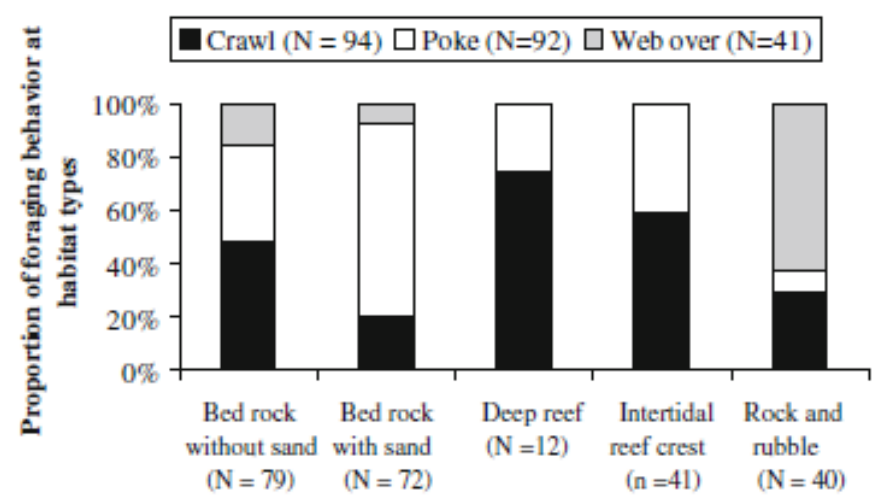


Table 3 Total number of observations for each transition departure among the five most frequent instantaneous foraging behaviors (Crawl (C), Poke (P), Web over (W), Moving (M) and Swimming (S))

\begin{tabular}{|c|c|c|c|c|c|}
\hline \multirow[b]{2}{*}{$\begin{array}{l}\text { Transition } \\
\text { departure }\end{array}$} & \multicolumn{4}{|c|}{ Habitat } & \multirow[b]{2}{*}{ Total number } \\
\hline & B & BRS & RU & RS & \\
\hline PM & 3 & 10 & 2 & 2 & 17 \\
\hline PW & 3 & 0 & 0 & 0 & 3 \\
\hline $\mathrm{PC}$ & 10 & 3 & 0 & 19 & 32 \\
\hline PS & 1 & 0 & 2 & 0 & 3 \\
\hline MP & 2 & 5 & 2 & 1 & 10 \\
\hline MW & 1 & 1 & 4 & 0 & 6 \\
\hline MC & 0 & 2 & 0 & 1 & 3 \\
\hline MS & 0 & 0 & 0 & 0 & 0 \\
\hline WP & 3 & 0 & 0 & 0 & 3 \\
\hline WM & 0 & 0 & 2 & 0 & 2 \\
\hline WC & 4 & 0 & 2 & 0 & 6 \\
\hline WS & 3 & 1 & 5 & 0 & 10 \\
\hline $\mathrm{CP}$ & 10 & 5 & 1 & 9 & 26 \\
\hline $\mathrm{CM}$ & 0 & 0 & 0 & 0 & 0 \\
\hline $\mathrm{CW}$ & 5 & 1 & 6 & 0 & 12 \\
\hline CS & 9 & 1 & 0 & 1 & 14 \\
\hline SP & 3 & 1 & 1 & 0 & 6 \\
\hline SM & 0 & 0 & 1 & 0 & 1 \\
\hline SW & 3 & 0 & 10 & 0 & 14 \\
\hline SC & 6 & 0 & 0 & 0 & 8 \\
\hline Total & 66 & 30 & 38 & 33 & 176 \\
\hline
\end{tabular}

Foraging sequences

The probabilities of different transitions among the five most frequent instantaneous foraging behaviors (crawl, poke, web-over, moving, and swimming) were calculated. This analysis will tell us about the mix of different strategies that the octopuses are using. Of 24 possible departure transitions, only three were not observed: moving to swimming, crawl to moving, and swimming to swimming. Considering only the 20 departure transitions observed at four habitats (Table 3), the chi-square probability analysis of departure in transition behavior (shift from one foraging behavior category to another) was significant for all habitats together $(n=176)$ (chi-square $=77.20, d f=19, P<0.001)$. The transitions for the deep reef were not considered, owing to the small number of instantaneous behavior units analyzed $(n=9)$.

The two transitions occurring more often than the $11 \%$ expected by chance were poke to crawl ( $18 \%$, $n=32)$, and crawl to poke $(14 \%, n=26)$. Poke to moving and swimming to web over also presented elevated frequencies of transition ( $9.7 \%$ and $8 \%$, respectively) when compared with the expected (3\% and $1.7 \%$, respectively) (Table 3 ). The transitions occurring less often than the expected by chance were poke to web over and vice versa (observed $1.7 \%$, and expected $4 \%, n=3$ for both), crawl to moving and vice versa (observed $0 \%$, expected $2.9 \%, n=0$ for both). 
To look at the possibility that foraging behavior sequences are fixed or that they are varied to suit the microhabitats of the different areas, we tested the transition frequency between the four habitats analyzed. The chi-square test was also significant ( $p<0.001$ for all analyses). The transitions occurring more often than the expected by chance in bed rock $(n=66)$ were crawl to poke and vice versa $(15.2 \%$ observed, $n=10$ for both) compared with 11.3\% expected, and crawl to swimming $(n=9)$ with 13.6\% observed compared with $5.6 \%$ expected. In the intertidal reef crest $(n=33)$, poke to crawl $(45 \%, n=19)$ and crawl to poke $(22 \%, n=9)$ were the most frequent. There were no transitions involving swimming and web-over behaviors in this habitat. In bed rock with sand $(n=30)$, poke to moving was the most frequent transition (33\%, $n=10)$, and in the small rock and rubble habitat $(n=38)$, swimming to web-over was the most frequent $(25 \%, n=10)$ (Table 3).

\section{Occurrence of foraging behavior versus environmental variables and individual characteristic (body size)}

To determine if foraging behavior occurrences were related to environmental and individual (body size) characteristic, the occurrence of the IFB categories were analyzed in relation to these variables. Multinomial logistic regression showed a significant relationship among IFB and the independent variables (chi-square $=114.75, d f=10, p<0.001$ ). There were significant effects of substrate (chi-square $=41, d f=3, p<0.001$ ), presence of sand and/or rubble (chi-square $=13.89, d f=3, p<0.001$ ), and octopus size (chi-square $=16.55, d f=6, p<0.025)$, but not of depth $(p>0.025)$, on the occurrence of foraging behaviors (crawl, poke, and web-over) (chi-square $=114.75, d f=10, p<0.001$ ).

Crawl was the most frequent in large octopuses (41\% of 91 crawl observations), on bed rock ( $87 \%$ of 91 ) with no sand $(75 \%)$. Poke was more frequent in small octopuses (45\% of 91 poke observations), on bed rock $(97 \%)$, and with no sand and/or rubble (52\%). Web-over was more frequent for large animals (64\% of 39 WO observations), with no observations in small octopuses, on bed rock (64\%) and with sand and/or rubble (69\%).

\section{Visual attacks}

Visual attack behavior occurred when a medium-sized octopus was crawling on bed rock and suddenly saw a small fish (Gobidea) nearby. In $<1 \mathrm{~s}(266 \mathrm{~ms})$, the octopus attacked the fish, first projecting two arms toward the fish, then jetting to the fish's crevice, trying to pull it out (Fig. 7). This foraging behavior occurred in Atalaia in shallow water ( $0.5 \mathrm{~m}$ depth). Such foraging behaviors were observed fewer than five times during this study, without success, characterizing them as opportunistic.

Fig. 7 Sequence of an Octopus insularis performing a visual attack on a small gobid fish
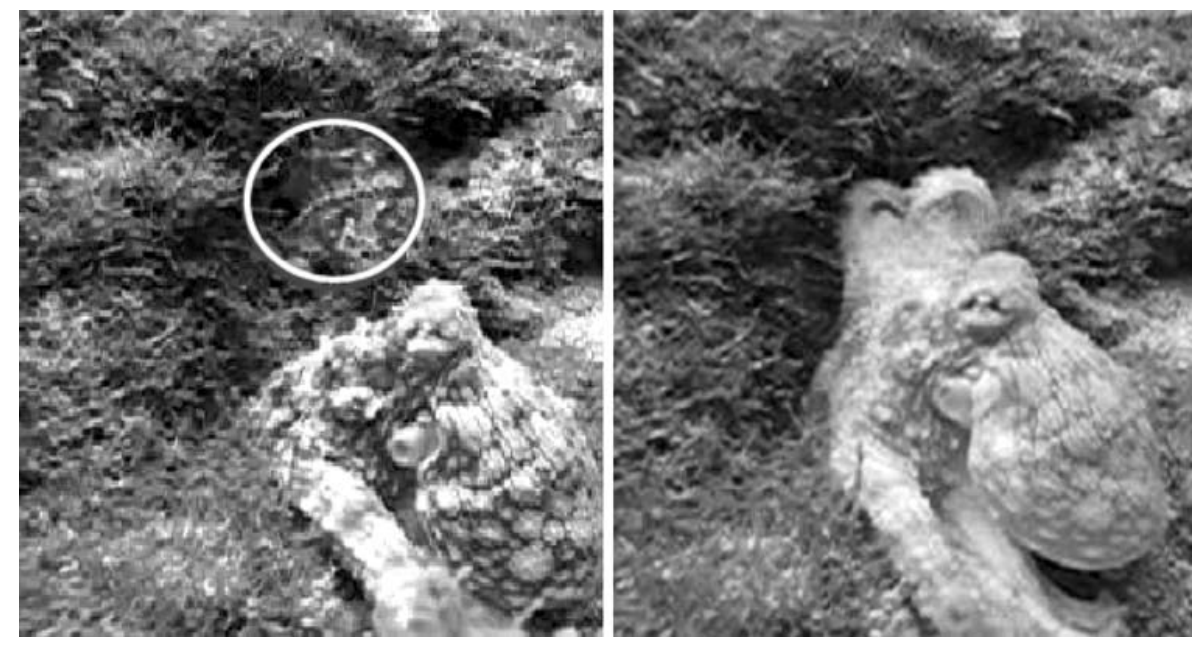


\section{Occurrence of body patterns}

To investigate changes in body patterns related to environmental and individual characteristics (body size) and with foraging behavior categories, body pattern occurrence was analyzed with these variables. Multinomial logistic regression showed a significant relationship between body patterns and the independent variables (chi-square $=148.71, d f=27, p<0.001$ ). There were significant effects of depth (chi-square $=21.665, d f=3, p<0.001$ ), foraging behavior category (chi-square $=118.26, d f=12$, $p<0.001$ ), presence of sand and/or rubble (chi-square $=45.500, d f=3, p<0.001$ ), and octopus size (chi-square $=14.76, d f=3, p<0.025)$. Substrate did not appear to influence the main body patterns $(p>$ 0.025).

Mottle was the most frequent pattern observed (146 observations). During poke and crawl this was the most frequent body pattern recorded $(68.1 \%$ and $59.3 \%$, respectively), whereas during swimming dorsal light-ventral blue green was the less frequent (71.9\%) (Fig. 8). When the octopus performed the webover, blotch was the most common pattern (38.5\%) followed by uniform dark (35.9\%) (Fig. 8). Mottle was the most frequent pattern at shallower depths (72\%) and in substrates without sand (64\%).

Blotch occurred more frequently in large animals (85\%) and medium depths (93\%), and in substrates with sand and/or rubble (89\%). Dorsal light-ventral blue green occurred more frequently during swimming (71.9\%) at mid-depth waters (81\%) (Fig. 8).

Fig. 8 Percentage of occurrence of main body patterns among five foraging behaviors

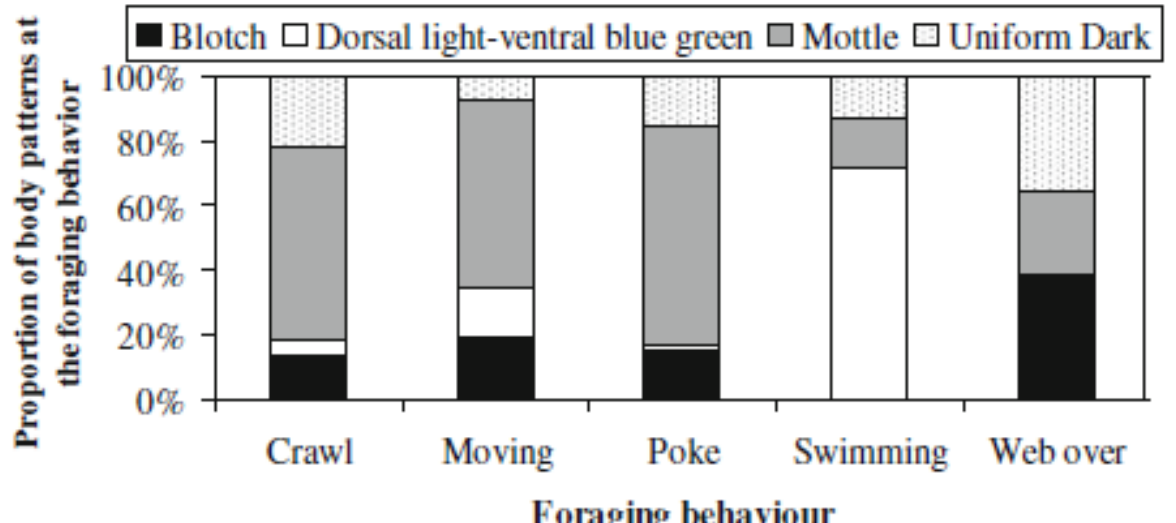

\section{Discussion}

This study assessed feeding ecology, foraging behavior, and defensive strategy during foraging, including the use of body patterns, to construct a general $O$. insularis foraging strategy in a shallow water reef system. The large proportion of two species of small crabs in the den remains, the intense search for food during short hunting trips, and the use of a mottle body pattern during most foraging trips, indicate that this species is a 'time-minimizing' forager, such as E. doXeini (Scheel et al. 2007) instead of a 'ratemaximizing' forager (Stephens et al. 2007). Foraging behavior sequences were characteristic of a tactile salutatory searcher, and to a lesser extent of a visual opportunist.

The wide ranging $O$. insularis diet, involving a large number of prey species (48), confirms the flexible diet common to other shallow water octopuses (Mather 1991a; Hanlon and Messenger 1996; Vincent et al. 1998; Smith 2003). However, the large proportion of only two crab species in the O. insularis diet seems to indicate that this species has a strong prey preference or an efficient hunting technique for the small 
crabs. This diet is similar to that of $O$. cyanea from Hawaii (Mather, in preparation) and O. vulgaris from the Caribbean (Anderson et al. 2008). Ambrose (1984) observed a similar pattern in O. bimaculatus, with 55 prey items but only three common species, and classified this species as a generalist predator, and one that can also be selective. Vincent et al. (1998) considered E. dofleini as a "switching" generalist, since the proportion of the five most frequent species found in den remains was also similar to the proportion available in the environment.

Although the general model predicts that prey size should increase with increasing predator size (Shoener 1971), and that energy density also increases with prey size (Scheel et al. 2007), the lack of shift in prey size in the $O$. insularis diet confirmed its preference for small prey over its entire benthonic life cycle. The minimal presence of lobster and the absence of the large crab Grapsus grapus in the remains, despite their high abundance in the shallow waters of Fernando de Noronha (J. Lins, personal communication), represents one of the 'time minimizing forager' characteristics, since small crabs can easily be found and caught under hard substrates by the $O$. insularis and their thin exoskeleton can be more easily broken or pulled apart with its strong arms and relatively deep web (Leite et al. 2008), a less time-consuming technique than drilling (Hartwick et al. 1981; MacQuaid 1994). Moreover, the relatively deep web can also be used as a trap during foraging and is able to retain more than one prey on the same trip.

The predominant poke and crawl foraging behavior was also observed for O. vulgaris (Mather 1991a) and O. cyanea (Forsythe and Hanlon 1997), and Mather stressed the importance of the tactile search in $O$. insularis foraging strategy. These foraging behaviors allowed the octopuses to find their main prey species hidden inside the rock and reef beds with the tip of their arms without the help of eyesight.

The search strategies employed by a given predator has commonly been thought as a trait dictated by evolution and not open to modification under changing environmental circumstances (O'Brien et al. 1990). However, the flexible foraging behavior sequences of $O$. insularis and their relationship with body size and several environmental variables point to a changeable foraging strategy.

The change of foraging behavior with a shift in habitats (more crawl on bed rock and reefs, web over on rock/rubble, and poke on bedrock with sand) suggests that octopuses in this same habitat adapt their foraging techniques to a specific mini-habitat. This pattern has been described by Forsythe and Hanlon (1997) for O. cyanea and Mather (1991a) for O. vulgaris. More crawl on rock for larger octopuses and more poke for small octopuses in this same habitat, in addition to more web over for large octopuses in rock/sand and rubble, suggest better selectivity for larger animals and different prey-finding strategies with octopus size.

Not only did foraging behaviors change with habitats, but also the transitions between the different behaviors. More poke to crawl and vice versa on bedrock and on intertidal reef crest may be a slower search pattern in a habitat with more opportunity, whereas crawl to swimming points to saltatory searching (O'Brien et al. 1989) for better places to forage. The transitions between web-over and move, swimming or crawl on substrates in small rock and rubble habitats also points to a saltatory foraging strategy in substrate with poor and good foraging areas.

The usual stop-and-go pattern observed for $O$. insularis while foraging is similar to the saltatory search pattern described by O'Brien et al. (1989), allowing the searchers to choose prey by scanning the entire search space while in a stationary position. Although studies on saltatory movement patterns have reported that animals only search for prey while pausing (O'Brien et al. 1990), and use the movement between pauses only to move into an unscanned space, $O$. insularis was able to search for food with many extended arms while crawling on favorable substrates. Moving and Swimming were only used by 
octopuses to go from a scanned to an unscanned area with more possibilities of success, thereby maximizing search time. Mather (1991a) and Forsythe and Hanlon (1997) found the same stop-and-go pattern for $O$. vulgaris and $O$. cyanea; however, these species only spent $25 \%$ and $12 \%$, respectively, of the time stationary (versus $51 \%$ for $O$. insularis).

Mather and O'Dor (1991) argued that if the risk is high, octopuses may maximize efficiency not by optimizing energy gain, but by avoiding the risk of injury or death. The stop-and-go pattern allows a balance between vigilance for predators and scanning for prey (O'Brien et al. 1990). The almost similar proportion of time spent by $O$. insularis in pause and moving during the foraging trips shows a balance between the risks of being preyed upon and the gain from detecting potential prey, consistent with high predator pressure (sharks, eels, and rays) in protected marine areas with very clear water, such as the Fernando de Noronha Archipelago.

Video analysis also showed that $O$. insularis probably used eyesight (in addition to touch) to choose its route and the best place to forage next, especially between foraging behavior transitions (manuscript in preparation). Along some habitat edges, the octopuses did not search the substrate using their arms, but rather used the head bob movement to scan the environment, changing from swimming to foraging behavior, especially to web-over or crawl, when swimming above a good foraging microhabitat. Studies revealed that cephalopods may use visual landmarks for orientation (Wells 1978; Boal 1996; Alves et al. 2008), suggesting the use of vision, especially for navigation (Mather 1991b). Others indicated that octopuses use eyesight to differentiate between shapes and size and even adopt different attack tactics accordingly (Hanlon and Messenger 1996).

Another use of eyesight was the unusual but important $O$. insularis opportunistic feeding strategy, which could also be classified as "ambush" or "sit-and-wait" searches. In Fernando de Noronha, the opportunistic attacks on crabs and fish that were larger and faster than the small crabs and mollusks usually found in the remains, were initiated by visual detection. The attack on these preys was observed only when the situation was favorable; for example, when the octopus was alert in the den entrance and the potential prey entered into its action area, thus minimizing energy waste and maximizing gain if the capture was successful. Catches of unusual prey by $O$. insularis were also observed at other sites and during similar opportunistic situations. A marine bird (Anous stolidus) was attacked and eaten in Saint Peter Saint Paul Archipelago and Rocas Atoll (Sazima and Almeida 2006) and newly hatched green turtles (Chelonia mydas) were caught during their massive exodus to the sea ( $T$. Leite, personal communication). The extremely fast response to visual detection and subsequent attack on small fish by $O$. insularis showed that sight plays an important role in opportunistic attacks. The infrequent occurrence of observations of these attacks in situ is probably due to their unexpected and brief nature, which requires time-consuming, frame by frame analysis for recognition.

\section{Foraging strategy versus body pattern}

The significant relationship between foraging behaviors and body patterns observed in this study suggests a clear linkage between the choices of behaviors and those of body patterns. $O$. insularis may maximize foraging by avoiding the risk of injury or death from predators by a primary defense pattern (crypis) (Hanlon and Messenger 1996). Examples are the general background resemblance (mottle) during the slower behavior near the background (moving, crawl, and poke), and the countershading pattern (dorsal light-ventral blue green) during swimming (see the $O$. insularis body pattern description in Leite and Mather 2008).

The relationship of body pattern with other variables, in addition to substrate characteristics, may also explain why Hanlon et al. (1999) did not find a cryptic O. cyanea pattern most of the foraging time, despite 
high predation pressure. The smaller $O$. insularis and animals in shallower water need more mottle as background matching than do bigger specimens in deeper water. The octopuses also used uniform dark instead of dorsal light-ventral blue green when swimming in deeper water, given that there is less visibility for distinguishing detail. Krajewski et al. (2009) also observed that $O$. insularis performed schooloriented mimicry while swimming near a group of small groupers in deeper water in Fernando de Noronha. The pattern observed on these occasions is also a deceptive resemblance pattern (longitudinal dark and white stripes), described not only for these species, but also for O. vulgaris (Hanlon and Messenger 2006).

The strategy of camouflage during most of the foraging behavior must be very important in minimizing the time risk to $O$. insularis as well as for its 'time-minimizing strategy'. Compared with $O$. cyanea and $E$. doXeini, $O$. insularis is smaller and hence more susceptible to predation. Moreover, Fernando de Noronha Archipelago is a tropical marine protection area, with many predators, including fishermen, and remarkably clear water (nearly $50 \mathrm{~m}$ visibility), a fact that makes it easier to find these octopuses.

Larger octopuses seem less vulnerable, and they exhibited the most visible pattern (blotch), especially during the web-over behavior, which is also a more visible behavior. This combination is possibly being used by $O$. insularis as a secondary defense to intimidate a predator from approaching, given that the web-over pattern and the blotches covering its body make it appear larger. The absences of this behavior and body pattern in small octopuses support this hypothesis.

\section{Conclusion}

Octopus insularis feeding appears to be affected not only by environmental factors, but also by the changes in its foraging strategies. As with other octopus species, it seems to be an opportunistic predator. However, it adopts several hunting tactics as a function of habitat variables and its body size, and it uses mainly chemotactile exploration to locate and feed on a wide variety of prey species. Despite $O$. insularis' varied diet, the large predominance of two species of small crabs in den remains, the intense search for food during short hunting trips, and the intense use of cryptic body patterns during foraging trips suggest that this species is a 'time-minimizing forager' instead of a 'rate-maximizing forager'.

Its feeding and foraging strategy seem to be consistent with a number of predictions based on optimal foraging models, with a balance between maximal energy intake and minimal energy waste (Stephens and Krebs 1986). However, due to the octopus's capacity for learning and changing tactics based on previous experience (Wells 1978; Mather 1994), the conventional foraging theory alone does not adequately explain the entire $O$. insularis foraging strategy (Anderson et al. 2008). O. insularis was able not only to change its hunting tactics and foraging behavior from time to time, but also to carry out alternative strategies, such as opportunistic visual attacks, depending on variables such as size, opportunity, and environmental conditions.

\section{Acknowledgments}

We thank the Administration of Fernando de Noronha and the Ministries of Environment (MMA/IBAMA) for their logistic support and the volunteers of UFRN and FURG who cooperated with the Weld samples. This study was supported by the Foundation Boticário for Environmental Protection; the Graduate School in Biological Oceanography at the Fundação Universidade Federal de Rio Grande (FURG), Dept. of Oceanography, Universidade Federal do Rio Grande do Norte; and grants from the Brazilian Research Council (CNPq) (TL and MH). 


\section{References}

Adamo SA, Ehgoetz K, Sangester C, Whitehorne I (2006) Signaling to the enemy? Body pattern expression and its response to external cues during hunting in the cuttlefish Sepia oYcinalis (Cephalopoda). Biol Bull 210:192-200. doi:10.2307/1542128

Alves C, Boal JG, Dickel L (2008) Short-distance navigation in cephalopods: a review and synthesis. Cogn Process 9:239-247. doi:10.1007/s10339-007-0192-9

Ambrose RF (1983) Midden formation by octopuses: the role of biotic and abiotic factors. Mar Behav Physiol 10:137-144

Ambrose RF (1984) Food preferences, prey availability, and the diet of Octopus bimaculatus Verrill. J Exp Mar Biol Ecol 77:29-44

Ambrose RF, Nelson BV (1983) Predation by Octopus vulgaris in the Mediterranean. PSZN1: Mar Ecol 4:251-261

Anderson RC, Wood JB, Mather JA (2008) Octopus vulgaris in the Caribbean is a specializing generalist. Mar Ecol Prog Ser 371:199-202

Boal JG (1996) A review of simultaneous visual discrimination as a method of training octopuses. Biol Rev 71(2):157-190

Cortez T, Castro BG, Guerra A (1995) Reproduction and condition of female Octopus mimus (Mollusca: Cephalopoda). Mar Biol 123:505-510

Eston VR, Migotto AE, Oliveira Filho EC, Rodrigues AS, Freitas JC (1986) Vertical distribution of benthic marine organisms on rocky coasts of the Fernando de Noronha Archipelago (Brazil). Bol Inst Oceanogr 34:37-53

Ferreira LM, Jesus F, Silva HA (1990) Plano de manejo do Parque Nacional Marinho de Fernando de Noronha. IBAMA/FUNATURA

Forsythe JW, Hanlon RT (1997) Foraging and associated behaviour by Octopus cyanea Gray, 1849 on a coral atoll, French Polynesia. J Exp Mar Biol Ecol 209:15-31

Fryxell JM, Lundberg P (1998) Individual behavior and community dynamics. Chapman \& Hall, New York

Greene PJ (1983) Selective predation in freshwater zooplankton communities. Int Rev Ges Hydrobiol 68:297-315

Hanlon RT, Hixon RF (1980) Body pattern and Weld observation of Octopus burryi Voss, 1950. Bull Mar Sci 30(4):749-755

Hanlon RT, Messenger JB (1996) Cephalopod behaviour. Cambridge University Press, Cambridge

Hanlon RT, Wolterding MR (1989) Behavior, body patterning, growth, and life history of Octopus briareus cultured in the laboratory. Am Malacol Bull 7:21-45

Hanlon RT, Forsythe JW, Joneschild DE (1999) Crypsis, conspicuousness, mimicry and polyphenism as antipredator defences of foraging octopuses on Indo-PaciWc coral reefs, with a method of quantifying crypisis from video tapes. Biol J Linn Soc 66:1-22

Hartwick EB, Tulloch L, Macdonald S (1981) Feeding and growth of Octopus doXeini. Veliger 24:129-138 Ibáñes CM, Chonge JV (2008) Feeding ecology of Enteroctopus megalocyathus (Cephalopoda: Octopodidae) in southern Chile. J Mar Biol Ass UK 88(4):793-798

Krajewski JP, Ronaldo RM, Sazima M, Sazima I (2009) Octopus mimicking its follower reef fish. J Nat Hist 43(3-4):185-190

Leite TS, Haimovici M (2006) Presente conhecimento da biodiversidade e habitat dos polvos (Cephalopoda: família Octopodidae) de águas rasas das ilhas oceânicas do nordeste brasileiro. In: Alves RJV, Castro JWA (eds) Ilhas Oceânicas Brasileiras - da Pesquisa ao Manejo, 1st edn. Ministério do Meio Ambiente (MMA), Brasília, pp 199-214

Leite TS, Mather J (2008) A new approach to octopuses' body pattern analysis: a framework for taxonomy and behavioral studies. Amer Malac Bull 24:31-41 
Leite TS, Haimovici M, Molina W, Warnke K (2008) Morphological and genetic description of Octopus insularis new species (Cephalopoda: Octopodidae), a cryptic species in the Octopus vulgaris complex from the tropical Southwestern Atlantic. J Molluscan Stud 74:63-74

Leite TS, Haimovici M, Mather J, Lins-Oliveira J (2009) Habitat, distribution, and abundance of the commercial octopus (Octopus insularis) in a tropical oceanic island, Brazil: information for management of an artisanal fishery inside a marine protection area. Fish Res 98:85-91

MacQuaid CD (1994) Feeding behaviour and selection of bivalve prey by Octopus vulgaris Cuvier. J Exp Mar Biolol Ecol 177:187-202

Maldonado H (1964) The control of attack by Octopus. Z Vgl Physiol 47:656-674

Martin P, Bateson P (1993) Measuring behaviour: an introductory guide. Cambridge University Press, Cambridge

Mather JA (1986) Sand digging in Sepia oYcinalis: assessment of a cephalopod mollusc's "fixed" behavior pattern. J Comp Psychol 100:315-320

Mather JA (1991a) Foraging, feeding and prey remains in midden of juveniles Octopus vulgaris (Mollusca: Cephalopoda). J Zool Lond 224:27-39

Mather JA (1991b) Navigation by spatial memory and use of visual landmarks in octopuses. J Comp Physiol A 168:491-497

Mather JA (1993) Octopuses as predators: implications for management. Recent Adv Cephalopod Fish Biol 27:5-282

Mather JA (1994) 'Home' choice and modification by juvenile Octopus vulgaris (Mollusca: Cephalopoda): specialized intelligence and tool use. J Zool Lond 233:359-368

Mather JA, O'Dor RK (1991) Foraging strategies and predation risk shape the natural history of juvenile Octopus vulgaris. Bull Mar Sci 49(1-2):256-269

Melo GAS (1999) Manual de identificação dos Brachyura (caranguejos e siris) do litoral brasileiro. Plêiade/FAPESP, São Paulo

O'Brien WJ, Evan BI, Browman $\mathrm{HI}$ (1989) Flexible search tactics and efficient foraging in saltatory searching animals. Oecologia 80:100-110

O'Brien WJ, Browman HI, Evans BI (1990) Search strategies of foraging animals. Am Sci 78:152-160

Quetglas A, Alemany F, Carbonell A, Merella P (1998) Biology and Fishery of Octopus vulgaris Cuvier, 1797, caught by trawlers in Mallorca (Balearic Sea, Western Mediterranean). Fish Res 36:237-249

Rios EC (1994) Seashells of Brazil. Editora FURG, Rio Grande Sazima I, Almeida LB (2006) The bird kraken: octopus prey on a sea bird at an oceanic island in the tropical West Atlantic. JMBA2Biodiversity records. Published on-line

Scheel D, Lauster A, Vincent TLS, Thiele R (2007) Habitat ecology of Enteroctopus dofleini from middens and live prey surveys in Prince William Sound, Alaska. In: Landman NH, Davis RA, Mapes RH (eds) Cephalopods present and past: new insights and fresh perspective. Springer, The Netherlands, pp 434-458

Shoener TW (1971) Theory of feeding strategies. Ann Ver Ecol Syst 2:369-404

Smale MJ, Buchan PR (1981) Biology of Octopus vulgaris of the east coast of South Africa. Mar Biol 65:1-12

Smith CD (2003) Diet of Octopus vulgaris in False Bay, South Africa. Mar Biol 143:1127-1133

Stephens DW, Krebs JR (1986) Foraging theory. Princeton University Press, Princeton

Stephens DW, Brown JS, Ydenberg RC (2007) Foraging behavior and ecology. University of Chicago Press, Chicago

Teixeira W, Cordani UG, Menor EA (2003) Caminhos do tempo geológico In: Linsker R (ed) Arquipélago de Fernando de Noronha o paraíso do vulcão. Terra Virgem Editora, São Paulo, pp 26-63

Vincent TLS, Scheel D, Hough KR (1998) Some aspects of diet and foraging behavior of Octopus dofleini (Wülker, 1910) in its northernmost range. PSZN: Mar Ecol 19:13-29

Wells MJ (1978) Octopus: physiology and behaviour of an advanced vertebrate. Chapman \& Hall, London 
Zar JH (1999) Biostatistical analysis, 4th edn. Prentice-Hall, New Jersey 